\title{
Economic Risk Assessment and Prevention of China's Investment in ASEAN Countries under the Background of "the Belt and Road Initiative"
}

\author{
Ruirui Ma, Chaohong Zhang, Li Li* \\ Pan-Asian business school, Yunnan Normal University \\ Kunming 650031, China \\ 1547893195@qq.com
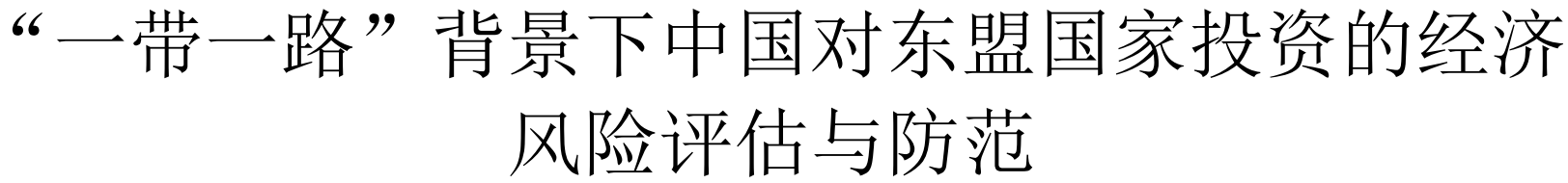 \\ 马芮芮, 张朝红, 李丽* \\ 云南师范大学泛亚商学院 \\ 昆明 650031, 中国 \\ 1547893195@qq.com
}

\begin{abstract}
Since the "the Belt and Road Initiative" initiative was put forward in 2013, China's investment in "the Belt and Road Initiative" countries along the belt and road has been increasing, which has played a positive role in promoting the political, economic, cultural and social development of the countries along the belt and road.However, everything has two sides. Behind the increasing investment, there are also more and more risks.Taking ASEAN countries as representatives, this paper firstly analyzes the current situation and characteristics of China's investment in ASEAN countries, then identifies and analyzes various risks faced by the investment, and finally conducts countermeasures research, signs bilateral and multilateral investment agreements, and establishes risk warning mechanism, which is extremely important for Chinese enterprises' investment.
\end{abstract}

Keywords-The Belt and Road Initiative; Risk identification; Economic risk; Sovereign credit risk.

摘要一自从 2013 年 “一带一路” 倡议提出后, 中国对 “一带一路”沿线国家的投资不断增加，对沿线国家的政 治、经济、文化以及社会的发展都起到了积极地促进作用。 但凡事具有双面性, 投资不断增加的背后, 也面临着越来越 多的风险。本文选取东盟国家为代表, 首先分析中国对东盟 国家投资的现状与特征，其次识别分析投资所面临的各种风 险, 最后进行对策研究, 其中签订双边及多边投资协定, 建 立风险预警机制等对中国企业的投资极为重要。 险

关键词一一带一路、风险识别、经济风险、主权信用风

\section{I. 引言}

随着 “一带一路”建设的不断深入，我国对沿线国 家的投资不断增加, 自从 2013 年以来, 中国对东盟国 家的区域直接投资存量从 2013 年的 356.7 亿美元上升到 2017 年的 890.1 亿美元, 直接投资流量从 72.7 亿美元上
升到 2017 年的 141.2 亿美元。但在投资总量上升的同 时，越来越多的投资失败事件发生，为促进我国对东盟 国家投资的健康发展, 我们要对投资风险进行识别分 析, 并提出相应的对策, 以使中国更好的对东盟国家进 行投资。

\section{II. 文献综述及理论基础}

经济活动的发生必然面临诸多风险。相比国内投 资，国外投资的风险更具有不确定因素，目前学者对投 资风险的研究主要如下：程云杰和武杰（2018）在中国 对转型经济体投资的经济风险评估及防范中, 将转型经 济体投资风险分为宏观经济风险、营商环境风险、主权 信用风险以及债务风险，通过运用主成分分析法对各个 风险进行度量和评估，从而从建立长效合作对话机制、 签订并完善双边协议、拓展投资领域及投资行业和建立 风险预警机制等方面做出防范措施 ${ }^{[3]}$; 钞鹏（2012）政 局动荡、法律限制、政策多变、文化差异等方面阐述了 政治风险产生的原因，并通过对政治风险进行分析，指 出跨国企业应当充分把握东道国政治风险，制定科学的 防控策略 ${ }^{[13]}$; 李原（2018）在分析 “一带一路” 沿线国 家风险特性的基础上，从政治社会风险、经济风险、法 律风险和主权信用风险构建国家风险评价指标体系，利 用因子分析法全面系统地衡量各国风险并划分出投资风 险的低、中、高三个区域，为改善我国对“一带一路” 沿线国家投资效益提供理论参考 ${ }^{[2]}$ 。

\section{III. 中国对东盟国家投资的现状与特征}

为了在 “一带一路” 背景下更好的研究中国对东盟 国家投资的风险，我们首先对东盟国家的现状，以及中 国目前对其投资的现状进行了解并分析。 
东盟成员国有马来西亚、印度尼西亚、泰国、菲律 宾、新加坡、文莱、越南、老挝、缅甸和柬埔寨。在 “一带一路” 建设中, 中国与东盟应不断深化经贸合 作, 共同应对当前世界经济的复杂变化, 实现互利共 赢。

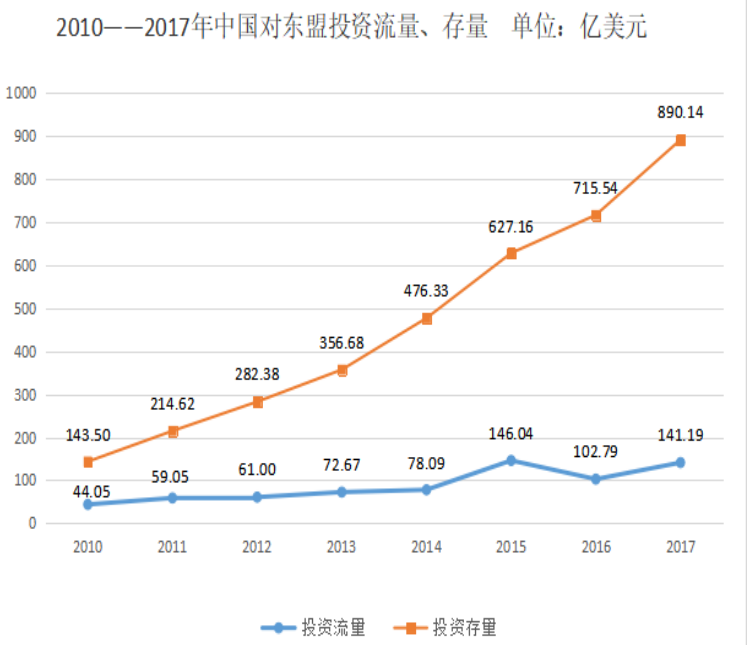

图 1. 2010一一2017 年中国对东盟投资流量、存量

数据来源：2017 年中国对外投资公报

近年来中国对东盟国家的直接投资持续上升。2017 年, 中国对东盟直接投资 141.2 亿美元, 占中国对外直 接投资的 $8.9 \%$ 。在中国对外直接投资流量前 20 位的目 的地区中, 东盟占 5 个。特别是在 2017 年, 中国对外 直接投资有较大幅度下降, 但对东盟国家投资依然保持 高增长势头, 可以看出中国企业对东盟投资十分活跃。 2018 年第一季度, 中国对东盟投资 25.6 亿美元, 同比 增长 $34.5 \%$ 。近年来中国对东盟国家投资的特点如下: 3.1 投资领域不断扩大。

早期中国对东盟十国的投资多集中在贸易、运输、 建筑承包等领域, 20 世纪 90 年代中期之后, 中国逐步 加大了对东盟国家制造业与服务业的投资。目前中国对 东盟十国的投资几乎遍及各个行业, 其中租赁和商务服 务业、制造业、电力、煤气及水的生产和供应业、批发 和零售业、采矿业、金融业、建筑业、农林牧渔业、交 通运输和仓储等行业是投资的主要行业。

3.2 投资分布不平衡。

新加坡是东盟十国中接受中国直接投资最多的国 家。2002 年以前, 泰国是东盟十国中吸收中国直接投资 （非金融类）最多的国家，约占中国对东盟十国投资的 $53.33 \%$ 。这一时期, 吸收中国投资最少的是菲律宾, 仅 占同期中国对东盟十国投资的 3.95\%。2003 年以来，新 加坡逐渐取代泰国成为东盟十国中接受中国直接投资最 多的国家。以 2017 年末的投资存量计, 新加坡大约占 中国对东盟十国直接投资的 $50.07 \%$, 是第二名印度尼 西亚的 4.3 倍, 而投资最少的文莱, 仅占 $0.25 \%$, 菲律 宾的投资存量比例持续下降，仅占 $0.92 \%$ 。

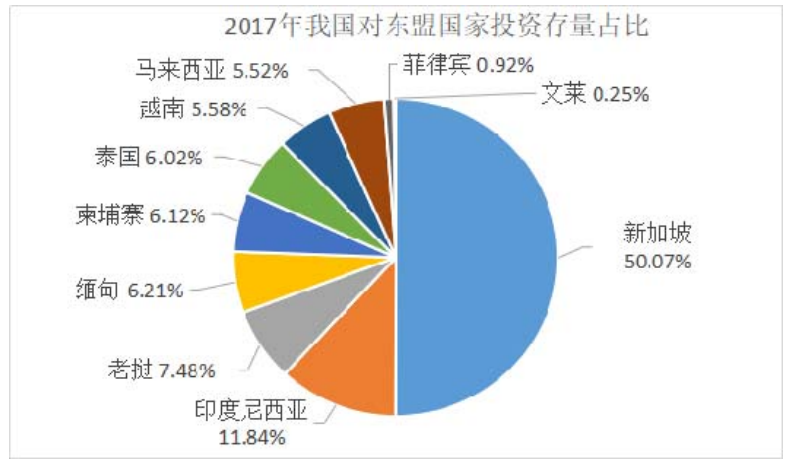

图 2.2017 年我国对东盟国家投资存量占比

数据来源：2017 年中国对外投资公报

3.3 投资方式与投资类型多样化。

中国企业在东盟十国的投资方式，从最初的绿地投 资发展到包括跨国并购、技术投资和 BOT 等多种形 式。投资类型主要包括加工贸易型、资源开发型、市场 开拓型、承包劳务型、服务贸易型等多种类型。

3.4 国有企业投资居于主导地位，民营企业投资成长迅 速。

众所周知, 国有企业特别是央企和发达省市的重点 国企, 它们资金实力雄厚、技术较为先进, 加之又有政 府扶持, 往往能在中国的海外投资中扮演重要角色。例 如, 中国国家电网公司入主菲律宾国家电网公司 $40 \%$ 的 股权、中国铝业公司在马来西亚兴建电解铝厂、神华集 团投资印度尼西亚大型煤电项目等。十余年来，中国民 营企业对东盟的投资相当活跃，投资金额迅速增长，已 成为推动中国对东盟投资的重要力量。目前中国民营企 业对东盟十国投资的行业相当广泛，主要涉及制造、农 业、矿业、贸易以及高科技等领域, 投资规模不断扩 大。

\section{IV. 投资所面临的各种风险}

\section{1 政治风险}

第一是政局动荡, 部分东盟国家因宗教问题战争不 断, 甚至政权变更, 从而影响东道国投资环境; 第二是 政策频繁变更, 东盟区域部分国家民主化程度较低, 政 权频繁变更会导致政策缺乏连续性。当东道国以公共利 益和环境保护等为借口对投资政策进行重大调整时, 如 通过提高税收、下达政府禁令、无故违约以及国有化政 策等对外国直接投资设置壁垒等, 投资项目会遭遇运营 困境或被迫叫停，陷入 “投资陷阱”; 第三是恐怖主义 蔓延, 东盟沿线地区恐怖主义活动频发, 伊斯兰地区极 端宗教势力猖獗, 恐怖组织势力从中东地区蔓延到中 亚、南亚、东南亚甚至中东欧, 国家暴恐事件不断。 4.2 经济风险

主要指东道国经济形势变化或经济政策调整导致对 外投资收益降低的可能性。“一带一路”沿线东盟国家 经济基础较薄弱, 市场经济制度不健全, 经济结构单 一, 经济稳定性较差; 金融系统较为脆弱, 国内金融市 场不发达, 容易受到世界经济低迷和国际金融市场波动 的影响。因此，对外直接投资面临的市场风险和运营风 险较为突出。市场风险主要表现在汇率风险和利率风 
险。“一带一路”沿线东盟国家大多数存在通货膨胀问 题, 这会对中国企业的投资产生消极影响。汇率风险主 要涉及东道国本币汇率的稳定性, 货币自由兄换程度和 外汇管制情况等。东盟地区欠发达国家较多，币种偏 小，国际流通性较差，汇率制度不健全，本币汇率频繁 波动情况时有发生。这将增加 “一带一路” 项目的货币 风险点, 高分散风险的难度。

4.3 法律风险

“一带一路”沿线的东盟国家大多是发展中国家和 转型经济体国家, 这些国家大多数有被殖民的历史, 所 以这些国家的法律体系大有不同。

表 1. 东盟国家法律体系分类表

\begin{tabular}{|l|l|}
\multicolumn{2}{c|}{ 表 1. 东盟国家法律体系分类表 } \\
\hline 法律体系分类 & 国家 \\
\hline 大陆法系国家 & 柬埔寨、越南、老挝 \\
\hline 海洋法系国家 & 缅甸、新加坡 \\
\hline 混合法系国家 & 菲律宾、泰国、印度尼西亚、文莱、马来西亚 \\
\hline
\end{tabular}

资料来源：根据 Wikipedia《List of national legal systems》整理

不同法律体系的国家, 所制定的法律规则是不一样 的，保护投资者的法律更是大有不同。一般来说，海洋 法系国家对投资者的保护力度要强于大陆法系国家, 海 洋法系比大陆法系有着更低的司法程序形式主义和更大 的司法独立性, 能够更好的促进合同履行和财产权的保 护。

不同的法律体系国家用不同的方式解决纠纷。大陆 法系更加注重法律的制定, 案件判决依据法规, 法官是 判决的关键。而海洋法系相对更宽泛, 案件的判断会受 之前类似案件判断的影响, 法官位于中立地位。

宗教法跟民族宗教关系密切, 不同的宗教信仰形成 不同法律体系, 导致在案件处理方法和保护投资者法律 两方面不同宗教国家各不相同。同样混合法系包括大陆 与海洋法系混合, 宗教与海洋法系混合, 宗教与大陆法 系, 法律差异较大。

东盟国家绝大多是发展中国家, 这些国家还存在法 律不完善, 朝令夕改等问题, 中国对其投资很有可能因 为对当地法律不熟悉而要面临法律费用和经营成本增加 的挑战。第一，一些国家在投资业、产业政策、以及土 地等方面法律法规不完善; 第二, 因我国企业不了解当 地法律法规而引起的劳资关系纠纷仲裁、知识产权权纠 纷和生态环境破坏; 第三, “一带一路”投资机制不一 致。因此了解被投资国法律滟源是降低法律风险的前 提。

4.4 文化差异风险

“一带一路” 沿线的东盟国家大多有着被殖民、被 压迫的历史, 也有着悠久的文化传统和浓厚的宗教信 仰, 宗教文化种类多, 一个国家内部也会交杂不同的民 族文化。表 2 是对 “一带一路” 沿线的东盟国家进行分 类, 主要的宗教有佛教、伊斯兰教、天主教。表中可以 看出信仰佛教的国家最多。

复杂交织的民族文化和宗教信仰, 容易产生民族本 位主义和宗教信仰冲突的风险。如果国内两大党派分别 支持不同的信仰, 当执政党派势力减弱就会加剧两派间 的争斗, 教派冲突和地区冲突风险程度上升。因此了解
被投资国民族文化, 宗教信仰, 社会习俗, 意识和价值 观念是顺利进行直接投资活动的前提。

表 2.东盟各国按宗教分类

\begin{tabular}{|l|l|}
\hline 宗教分类 & 国家 \\
\hline 佛教占主导国家 & 新加坡、泰国、柬埔寨、缅甸、越南、老挝 \\
\hline 伊斯兰教占主导国家 & 印度尼西亚、文莱、马来西亚 \\
\hline 天主教占主导国家 & 菲律宾 \\
\hline
\end{tabular}

资料来源：根据中国民族宗教网《宗教与 “一带一路”建设》整理

\section{5 主权信用风险}

主权信用风险是指一国以国家主权作为担保，向 IMF、世界银行以及其他国家借款并产生违约的可能 性。东道国政府违反合约造成的经济损失不容忽视, 国 家主权信用评级在一定程度上代表东道国政府的违约风 险, 主权信用越高, 投资面临损失的可能性就越小。如 果该国主权信用评级较低, 则易形成主权信用危机, 对 外国投资企业造成一定的利益损失，在一定程度上也会 影响本国投资环境的稳定性和连续性。目前具有一定权 威性的世界三大国际主权信用评级机构分为标准普尔公 司、穆迪投资者服务公司和惠誉国际信用评级公司。但 三大机构评级都对中国国情单独考虑, 而随着中国综合 国力不断提升，各国对华关系、经贸往来、民间交往等 对更加密切, 这也将会影响到中国的对外投资。因此, 符合中国国情的评级或许更具有参考价值。

中国海外投资风险评级体系，纳入经济基础、偿债 能力、社会弹性、政治风险、对华关系五大指标, 共 41 个子指标。在评级上充分吸收了国内外评级机构的 优秀理论，并结合中国对外投资的实际，将各国对华关 系也做了重点考核, 从而能更有针对性的衡量我国海外 投资的风险，东盟国家历年国家风险评级如下：

表 3. 东盟国家 2015- - 2019 年主权信用风险评级

\begin{tabular}{|c|c|c|c|c|c|}
\hline & 2019 & 2018 & 2017 & 2016 & 2015 \\
\hline 新加坡 & $\mathrm{AA}$ & $\mathrm{AA}$ & $\mathrm{AA}$ & $\mathrm{AA}$ & $\mathrm{AA}$ \\
\hline 马来西亚 & $\mathrm{BBB}$ & $\mathrm{A}$ & $\mathrm{A}$ & $\mathrm{BBB}$ & $\mathrm{A}$ \\
\hline 菲律宾 & $\mathrm{BBB}$ & $\mathrm{BBB}$ & $\mathrm{BBB}$ & $\mathrm{BBB}$ & $\mathrm{BBB}$ \\
\hline 印度尼西亚 & $\mathrm{BBB}$ & $\mathrm{BBB}$ & $\mathrm{BBB}$ & $\mathrm{BBB}$ & $\mathrm{BBB}$ \\
\hline 泰国 & $\mathrm{BBB}$ & $\mathrm{BBB}$ & $\mathrm{BBB}$ & $\mathrm{BBB}$ & $\mathrm{BBB}$ \\
\hline 老挝 & $\mathrm{BBB}$ & $\mathrm{BBB}$ & $\mathrm{BBB}$ & $\mathrm{BBB}$ & $\mathrm{BB}$ \\
\hline 柬埔寨 & $\mathrm{BBB}$ & $\mathrm{BBB}$ & $\mathrm{BBB}$ & $\mathrm{BBB}$ & $\mathrm{BB}$ \\
\hline 越南 & $\mathrm{BBB}$ & $\mathrm{BBB}$ & $\mathrm{BBB}$ & $\mathrm{BBB}$ & $\mathrm{BB}$ \\
\hline 缅甸 & $\mathrm{BBB}$ & $\mathrm{BBB}$ & $\mathrm{BBB}$ & $\mathrm{BBB}$ & $\mathrm{BB}$ \\
\hline 文莱 & - & - & - & - & - \\
\hline
\end{tabular}

由上表可知, 东盟国家主权信用风险评级除马来西 亚上下波动外, 总体保持稳定。同时, 东盟国家主权信 用风险普遍较高, 仅新加坡为低风险。对于东盟国家来 说, 大部分极易形成主权信用危机, 对我国投资企业造 成一定的利益损失, 在一定程度上也会影响我国投资环 境的稳定性和连续性。

\section{V. 对策研究}

5.1 全面了解被投资国政治、经济和文化环境。

被投资国的政治、经济和文化环境直接决定着外商 投资的环境、政策和发展空间，因此对其要有一个全面 的了解。政治环境主要是指被投资国的政治状态，中国 企业要对其政局的安定性, 国家政策和法律体系的完整 
性进行认真考量, 对是否有恐怖主义势力进行辨别。经 济环境主要是一个国家的经济发展状况, 一定程度上决 定着投资能够获得预期收益的可能性。然而每个国家经 济状况都大有不同, 所以中国对外投资企业要根据投资 行业和投资领域选择被投资国，并根据不同经济情况制 定投资计划，做到因地制宜。文化环境是最容易被投资 者忽略的，中国企业对东盟国家进行投资，表现出的是 资本在国际间的流动，同时也伴随着不同文化之间的交 流、碰撞和融合, 所以文化背景的不同还是要引起中国 企业的重视。

5.2 加强政策沟通，扩大并完善多边贸易协定对投资风 险的规避作用。

中国可以积极与东盟国家签订双边或多边投资协 定。稳定的政治基础和较强的经济能力将为此类国家遵 守并落实签订的协议提供基础, 可以大幅且有效降低我 国境外投资可能面临的政治风险和经济风险。例如，当 前美国已经与全球 100 个政治和经济环境较为稳定的国 家签订了双边投资保护协定，打造了良好的合作基础。

针对此类国家保持良好的外交关系, 以政治外交促进经 济合作, 最终达成贸易外交协议的签订和落实。本文认 为中国政府应进一步以 《中国与东盟全面经济合作框架 协定》为依据, 扩大与东盟国家经贸合作的覆盖面的广 度和深度。

5.3 加强民间文化交流, 减小文化与制度距离对投资风 险的影响。

当前, 中国城市化进程的加快和供给侧改革进程的 加快也迫切需要加强与东南亚地区高新技术领域的合 作, 发展长期经贸往来。需要指出的是, 中国同东盟国 家在政治体制与文化习俗等方面存在着显著差异, 而这 一差异的增大将增加投资的风险性, 削弱投资对贸易的 促进效应。因此, 当今社会文化交流产生的文化认同感 和情感纽带, 对国家投资和贸易产生的影响不可小觑。 中国要利用华人华侨优势, 通过举办文化主题活动、设 立文化交流民间组织等方式传播中华文化, 正确宣传中 国 “一带一路” 倡议, 树立和平友好的国际形象。在形 式各异的活动中, 增进中国与 “一带一路” 倡议沿线国 家国民的共鸣, 提高东道国政府和国民的信任度, 有效 减少社会和文化因素造成的投资风险。

5.4 提高风险意识, 做好风险评估, 建立风险预警机 制。

企业要对东盟国家投资经济风险进行识别和评估, 建立一套合理有效的风险评估及预警机制。通过前文分 析我们可知, 东盟国家大多数是发展中国家, 社会发展 落后, 处于转型阶段, 社会经济发展单一, 极易受全球 经济的干扰, 中国投资企业要对这些经济风险进行评 估。对投资经济风险评估的现有分析方法是主成分分析 法和因子分析法等, 中国对外投资企业选择合理的风险 评估机制来对投资的风险进行度量, 从而及时提出对策 来进行合理的规避, 以有效的减少企业在投资过程中因 风险评估不足而造成的经济损失。
VI. 总结

本文在 “一带一路” 背景下, 通过中国对东盟国家 的经济风险评估及防范的分析, 本文得出以下几点结 论。

中国在 “一带一路” 沿线国家的投资规模在不断扩 大, 对东盟国家投资比例也在不断提高, 随之而来的投 资风险也在增多, 我们要在识别评估的基础上进行合理 的规避; 本文选取东盟作为对外投资的研究对象, 发现 国家的发展程度不同，所面临的风险也不尽相同，中国 对外投资企业要针对具体每个国家进行单个分析并定制 个性化的投资计划，来降低投资风险; 在全球化的大背 景下, 中国已发展成为全球第二大经济体, 坚持走出去 战略进行对外投资, 是时代发展的必然趋势, 所以中国 应该选择适合投资的国家和行业进行投资，从而带动其 经济的持续发展。

本文的不足之处在于, 只是具体分析了每种风险, 并提出了相应的对策，但并未对每个国家每种风险进行 数字化的度量, 从而提出一个对东盟地区的最优投资组 合, 后续将会对此做更深入的研究。

\section{参考文献}

[1] 张栋, 许燕, 张舒缓.”一带一路” 沿线主要国家投资风险识别与 对策研究. 东北亚论坛, 2019(03) : 19-21.

[2] 李原,汪红驹.”一带一路” 沿线国家投资风险研究.河北经贸大学 学报,2018(04):47-48.

[3] 程云洁,武杰.中国对转型经济体投资的经济风险评估及防范. 经济 热点,2018(09).

[4] 陶眉辰.”一带一路”下中国对外基础设施投资风险研究.首都经 济贸易大学, 2017 .

[5] 张帅,刘文翠,”丝绸之路经济带”背景下哈萨克斯坦投资风险测 度及预警研究.统计与信息论坛,2016(04):34-35.

[6] 张梦男.”一带一路” 背景下东盟国家投资风险分析.南京信息工 程大学, 2017 .

[7] 吕志勇,王毓雯,王凯妮.”一带一路” 战略下中国企业海外投资的 风险管理研究.东北亚论坛,2019(03):40-42.

[8] 谢孟军.政治风险对中国对外直接投资区位选择影响研究.国际经 贸探索,2015(09):66-88.

[9] 胡伟,孙浩凯.”一带一路” 视角下我国企业对外直接投资的风险 及防范对策分析. 湖北经济学院学报 (人文社会科学 版),2016,(03):56-58.

[10] 张明.直面”一带一路” 的六大风险.国际经济评论,2015(04):38-41,

[11] 张静中,王文君,李敏.”一带一路” 发展战略背景下东盟投资环境 评价研究.金陵科技学院学报(社会科学版),2016,30(03):12-17.

[12] 李锋.”一带一路”沿线国家的投资风险与相应对策.中国流通经 济,2016,30(02): 115-121.

[13] 钞鹏.对外投资的政治风险识别.西南大学学报,2012(08).

[14] Al-Abri A,Bashestani H,Foreign investment and real exchange rate volatility in emerging Asian countries,Journal of Asian Economics,2015,(37):34-47.

[15] Anil K.Jain,Data Clustering:50 Years Beyond K-means,Pattern Recognition Letters,2010,31(08):651-666.

[16] X. W. Ding,W. Wang, G. H. Huang, A Two-Step Water-Management Approach for Nuclear Power Plants in Inland China, Journal of Risk Analysis and Crisis Response, December 2014, Pages 184-202. 